\title{
Milk-Derived Extracellular Vesicles Suppress Inflammatory Cytokine Expression and Nuclear Factor- $\kappa B$ Activation in Lipopolysaccharide-Stimulated Macrophages
}

\author{
Susanne R. Ascanius ${ }^{1}$, Maria S. Hansen ${ }^{1}$, Marie S. Ostenfeld ${ }^{2}$ and Jan T. Rasmussen ${ }^{1, *}$ \\ 1 Department of Molecular Biology and Genetics, Aarhus University, 8000 Aarhus, Denmark \\ susanneascanius@hotmail.com (S.R.A.); msh@mbg.au.dk (M.S.H.) \\ 2 Arla Foods Ingredients Group P/S, 8260 Viby, Denmark; mstos@arlafoods.com \\ * Correspondence: jatr@mbg.au.dk
}

\section{check for}

updates

Citation: Ascanius, S.R.; Hansen, M.S.; Ostenfeld, M.S.; Rasmussen, J.T. Milk-Derived Extracellular Vesicles Suppress Inflammatory Cytokine Expression and Nuclear Factor- $\mathrm{KB}$ Activation in

Lipopolysaccharide-Stimulated Macrophages. Dairy 2021, 2, 165-178. https://doi.org/10.3390/dairy 2020015

Academic Editor: Sven Dänicke

Received: 20 January 2021

Accepted: 22 March 2021

Published: 24 March 2021

Publisher's Note: MDPI stays neutra with regard to jurisdictional claims in published maps and institutional affiliations.

Copyright: (C) 2021 by the authors. Licensee MDPI, Basel, Switzerland. This article is an open access article distributed under the terms and conditions of the Creative Commons Attribution (CC BY) license (https:// creativecommons.org/licenses/by/ $4.0 /)$

\begin{abstract}
In milk and milk products, small membrane-enclosed vesicles can be found, commonly termed extracellular vesicles (EVs). Milk-derived EVs have previously been suggested to have immunoregulatory properties, especially important for infants without a fully functioning immune system. In the present study, EV fractions were isolated from human milk, mature and colostrum bovine milk, and two dairy fractions, and successively surveyed for their immunomodulating effects on lipopolysaccharide (LPS)-stimulated macrophages (RAW264.7). RAW264.7 cell material and supernatant were evaluated by monitoring degradation of $\mathrm{I} \kappa \mathrm{B} \alpha$ in the NF- $\kappa \mathrm{B}$ pathway, and IL-6 and IL-1 $\beta$ cytokine production, using Western blotting and enzyme-linked immunosorbent assaying, respectively. The results revealed that preincubation with EVs derived from raw human and bovine milk lowered the LPS-activated response of the NF- $\mathrm{B}$ p pathway. Additionally, it was found that preincubation with EVs, from human and bovine milk as well as dairy whey or skim milk-derived fractions, decreased secretion of proinflammatory cytokines from LPS-activated RAW264.7 cells. The findings that milk-derived EVs can change the inflammatory response in macrophages support the notion that milk EVs have an important role in mother-to-infant communication and protection of a newborn.
\end{abstract}

Keywords: extracellular vesicles; milk; dairy; whey; infant nutrition; cytokines; NF-кB; inflammation

\section{Introduction}

Extracellular vesicles (EVs) are secreted from most cells and can therefore be found in body fluids including urine, saliva, blood, and milk. EVs have proven important in facilitating communication between cells by transfer of cargo such as proteins, mRNA, and microRNA (miRNA). The term extracellular vesicles covers both exosomes (20-200 nm) and microvesicles (100-1000 nm). The two types of vesicles differ in biogenesis, but because of overlapping sizes and densities they are difficult to separate [1,2]. EVs are currently receiving a great deal of attention in different fields due to their biological functions as biomarkers, and a huge potential in therapy as an instrument facilitating drug delivery [3-5].

EVs have been found and described in both human and bovine milk [4]. Additionally, EVs are detected in commercially available infant formula; however, these EVs were devoid of miRNA [6-8]. Cell studies have shown that intestinal cells can take up EVs from bovine milk (bEVs) and miRNA have been found intact inside of EVs after simulated gastrointestinal digestion $[9,10]$. Uptake and intracellular transport of bEVs go through the conventional endocytic endosomal pathway [11]. Biological activity of bEVs has been described in a row of investigations, e.g., immune modulating effects have been demonstrated in human peripheral blood mononuclear cells and T regulatory cells [12]. These effects might be of great importance to newborns, as the bEVs possibly convey 
extra protection in young infants, whose immune systems are not fully developed at birth [13]. The innate immune system is the primary acting immune defense in newborns, and macrophages play a big role in this system $[14,15]$. Macrophages constitute the primary surveillance throughout the gastrointestinal tract and are responsible for communication with the rest of the immune system. Therefore, they are often used in immunological studies [16-18].

In bovine milk, EVs constitute $35-40 \%$ of the phospholipid found in major membrane structures, whereas the remaining can be attributed to the milk fat globules in the cream layer [19]. The globules (size: 0.1 to $15 \mu \mathrm{m}$, avg: $4.5 \mu \mathrm{m}$ ) contain the triacylglycerol synthesized in the mammary gland and facilitate solubilization in milk by envelopment in a tripartite membrane structure known as the milk fat globule membrane (MFGM) [20]. Besides delivering important lipids to the infant, this complex membrane and its molecular content has been extensively explored for its bioactive health related properties [21].

Newborns require immunological protection, because they are coming from the intrauterine sterile environment into a world full of foreign pathogens [22]. Breastmilk provides several immune-modulating components; immunoglobulins, living leucocytes, proteins such as lactadherin, oligosaccharides, and bioactive lipids $[13,23]$. The innate immune defense system provides a quick immune response by activating immune cells and releasing cytokines. Lipopolysaccharides (LPS), found on the surface of Gram-negative bacteria, are commonly used as a trigger of inflammation through their recognition by tolllike receptor 4 (TLR4) [24-26]. TLR4 can be found on the surface of resident macrophages lining the lamina propria of the gastrointestinal tract in both newborns and adults. TLR4 binding of LPS initiates the nuclear factor-kappa $\mathrm{B}(\mathrm{NF}-\mathrm{kB})$ pathway leading to production of proinflammatory cytokines like IL- 6 and IL-1 $\beta$, resulting in fever and in worst case sepsis [16,17]. The murine macrophage cell line RAW264.7 has often been used for immunological studies of the gut $[25,27,28]$. It has also been used to test immunological effects of milk proteins and EVs $[5,8,18]$. These macrophages display TLR4 on their surface and are therefore an important part of the signaling cascade during inflammation, especially in infants with a developing immune system [14]. Thus, the RAW264.7 cell line was used as model in the conducted experiments.

The present study investigated the ability of EVs isolated from raw milk and dairy fractions to alter activation of the NF- $\mathrm{KB}$ pathway and cytokine secretion by cultured RAW264.7 cells, and thereby demonstrates that these EV isolates have possible effects on the intestinal immune system.

\section{Materials and Methods}

\subsection{Materials and Reagents}

Size exclusion chromatography column material Sephacryl-500 was obtained from GE Healthcare (Uppsala, Sweden). Dialysis tubes were purchased at Medicell International Ltd. (London, UK). Polyethylene glycol 20,000 was obtained from Alfa Aesar (Thermo Fischer, Kandel, Germany). RAW264.7 cells were purchased from Cell Lines Service GmbH (Eppelheim, Germany). Reagents used for cell culturing were obtained at Gibco (Thermo Fischer Scientific, Hillsboro, OR, USA) and Sigma-Aldrich (St. Louis, MO, USA). Phenol reagent and dimethyl sulfoxide were obtained from Merck (Darmstadt, Germany). Primary antibody (AB) mouse anti-human CD81 clone 12C4, was obtained from Cosmo Bio, Tokyo, Japan. In-house produced rabbit anti-bovine PAS-7/lactadherin and rabbit anti-bovine $\beta$-casein peptide AB (residues 44-54) (Eurogentec, Liège, Belgium), secondary AB pig antirabbit was obtained from Dako (Hamburg, Germany). Primary AB IkB $\alpha$ mouse \#4814 and secondary HRP-conjugated horse anti-mouse AB \#7076 were purchased from Cell Signaling Technologies (Denver, MA, USA). Primary $\beta$-actin mouse AB \#A5441 and secondary rabbit anti-mouse AB \#A43121 were from Sigma-Aldrich (St. Louis, MO, USA). Buffer reagents were obtained from VWR chemicals (Leuven, Belgium) and Sigma-Aldrich GmbH (St. Louis, MO, USA). 


\subsection{Isolation Procedure for Extracellular Vesicles in Milk}

Isolations of EVs were made from $1 \mathrm{~L}$ of fresh bovine milk obtained from a local farm or dairy fractions from Arla Foods Ingredients (AFI, Denmark). Dairy fractions included a phospholipid-enriched whey protein concentrate (WPC-PL), and a phospholipid enriched product derived from a micellar casein isolate (MCI-PL). The dairy fractions were collected before and after the industrial spray drying process, therefore referred to as "wet" or "dry" fractions (wet WPC-PL, wet MCI-PL, dry WPC-PL, dry MCI-PL). The EV isolation was performed as described by Blans et al. 2017 [29]. All milk samples were pre-cooled to $4{ }^{\circ} \mathrm{C}$ and $0.5 \mathrm{mM}$ of the protease inhibitor phenylmethane sulfonyl fluoride was added prior to isolation. All steps were performed at $4{ }^{\circ} \mathrm{C}$. Milk samples were centrifuged at $3400 \times g$ for $35 \mathrm{~min}$ to pellet cell debris, and the upper cream layer was removed to obtain a skim milk fraction. Next, the skim milk was centrifuged at 20,000 $\times g$ for $60 \mathrm{~min}$. From the middle of the centrifugal tubes, clear milk serum was collected and $25 \mathrm{~mL}$ were subjected to size exclusion chromatography (SEC) using a Sephacryl S-500 column $2.5 \times 88 \mathrm{~cm}$ $(432 \mathrm{~mL})$ in $0.2 \mu \mathrm{M}$ filtered PBS supplemented with EDTA $\left(50 \mathrm{mM} \mathrm{NaH}_{2} \mathrm{PO}_{4}, 0.15 \mathrm{M} \mathrm{NaCl}\right.$, $20 \mathrm{mM}$ EDTA, pH 7.4) as running buffer. Dairy fractions (205 mg protein $/ 10 \mathrm{~mL}$ running buffer) were subjected to SEC using equivalent conditions. Dry samples were dissolved by gentle rotation for two hours at room temperature (RT). Absorbance at $280 \mathrm{~nm}$ was measured on all eluting fractions. The first peak, known to contain the EVs, was pooled and up-concentrated by reverse osmosis dialysis in a dialysis tube with a cut-off at 12-14 kDa against $10 \%$ polyethylene glycol $20,000(w / v)$ dissolved in PBS, pH 7.4 overnight at $4{ }^{\circ} \mathrm{C}$. EV isolates were stored at $-80^{\circ} \mathrm{C}$ until use. The human breastmilk sample $(40 \mathrm{~mL})$ was treated identically to the bovine samples, yet on a separate column of similar size and under the same buffer conditions as the bovine milk samples.

\subsection{Formation of Proteoliposomes}

A vesicle control was made as follows. Phospholipids dissolved in chloroform were mixed in the following ratio; 25\% 3-snphosphatidylethanolamine (Sigma, St. Louis, MO, USA), 10\% 2-alpha-phosphatidylinositol sodium salt, 10\% L-alpha-phosphatidylserine, $30 \%$ L-alpha-phosphatidylcholine, and 25\% sphingomyelin (Avanti ${ }^{\circledR}$, Alabaster, AL, USA). After mixing, multilamellar vesicles in a variety of different sizes and compositions were created. After evaporating the chloroform under nitrogen gas, the phospholipids were resuspended in filtered PBS with $0.1 \%$ deoxycholate. The solution was frozen and thawed ten times and forced through a $0.1 \mu \mathrm{m}$ filter in a mini extruder (Avanti ${ }^{\circledR}$, Alabaster, AL, USA). Next, milk fat globular membrane (MFGM) protein, dissolved in PBS buffer, was incorporated into the liposomes in a 4:1 ratio by rotating for $2 \mathrm{~h}$ at RT. MFGM protein was isolated from $12 \mathrm{~L}$ of bovine milk as described by Hvarregaard et al. 1996 [30]. Lastly the proteoliposomes were dialyzed for seven days at $4{ }^{\circ} \mathrm{C}$ in PBS buffer, in a dialysis tube with a cut of 12-14 kDa, with PBS buffer changed every other day.

\subsection{Determination of Protein Concentration}

To determine protein concentration in the EV isolates, and thereby being able to quantify the EVs, a modified Lowry assay was performed [31,32]. Bovine serum albumin (Sigma Aldrich, St. Louis, MO, USA) was used to make a serial dilution which served as a standard curve. All samples and standards were run in triplicate and subjected to the following procedure: $45 \mu \mathrm{L}$ sample was mixed with $5 \mu \mathrm{L} \mathrm{10 \%} \mathrm{SDS} \mathrm{and} 50 \mu \mathrm{L}$ alkaline $\mathrm{Cu}$-reagent and incubated for $10 \mathrm{~min}$ at RT. Then $200 \mu \mathrm{L}$ phenol reagent $(2.78 \mathrm{~mL}$ Folin Ciocalteau phenol in $50 \mathrm{~mL} \mathrm{H}_{2} \mathrm{O}$ ) was added and samples were heated to $55^{\circ} \mathrm{C}$ for $5 \mathrm{~min}$. After a quick cool down on ice, absorption was measured at $630 \mathrm{~nm}$.

\subsection{Cell Culture Maintenance}

Murine macrophages of the cell line RAW264.7 were used for cell culture experiments. The cells were maintained in high glucose Dulbecco's Modified Eagle Medium (DMEM) 
with $10 \%$ fetal bovine serum and $1 \%$ penicillin/streptomycin and kept at $37^{\circ} \mathrm{C}$ and $5 \%$ $\mathrm{CO}_{2}$.

\subsection{EV Labelling and bEV Uptake}

In order to detect RAW264.7 cells' ability to take up bEVs, the bEVs were labeled using lactadherin conjugated to a fluorophore as described by Hansen et al. 2020 [11]. Briefly, bEVs incubated with $200 \mathrm{nM}$ lactadherin-Alexa Fluor (Thermo Fischer Scientific, Hillsboro, OR, USA) for $24 \mathrm{~h}$ at $37^{\circ} \mathrm{C}$. Afterwards, unbound lactadherin-Alexa Fluor was separated from EVs by SEC using a Sephacryl S-500 column with $0.2 \mu \mathrm{m}$ filtered PBS buffer ( $50 \mathrm{mM}$ $\mathrm{NaH}_{2} \mathrm{PO}_{4}, 0.15 \mathrm{M} \mathrm{NaCl}, \mathrm{pH}$ 7.4). The presence of labelled EVs in the resulting fractions from SEC was confirmed by measuring the fluorescence (excitation wavelength $490 \mathrm{~nm} / \mathrm{emission}$ wavelength $525 \mathrm{~nm}$ ) (EnSpire Multimode 96-well Plate Reader; PerkinElmer). The labelled EVs were used for bEV uptake experiments by RAW264.7 cells seeded at a density of 6000 cells/well and grown for 3 days. One day before the experiment, medium was changed to serum-free DMEM. Then the cells were subjected to bEVs in different time intervals $(1,4$, 7,18 , or $24 \mathrm{~h}$ ) or different bEV concentrations $(10$ or $50 \mu \mathrm{g} / \mathrm{mL})$. After bEV treatment, the RAW264.7 cells were washed three times in citrate buffer $(10 \mathrm{mM}$ sodium citrate, $0.05 \%$ Tween 20, pH 6.0) to remove non-internalized bEVs followed by one neutralizing PBS wash before cell lysis with $1 \%$ Triton X-100 lysis buffer. Fluorescence was then measured using a microplate reader (PerkinElmer, Watham, MA, USA).

\subsection{Cell Viability}

Cell viability was assessed using a 3-(4,5-dimethylthiazol-2-yl)-2,5-diphenyltetrazolium (MTT) assay. RAW264.7 cells were seeded in 96-well plates at a density of 6000 cells/well and grown for 2 days followed by treatment with either 10, 50, or $100 \mu \mathrm{g} / \mathrm{mL}$ of EV isolate for $4 \mathrm{~h}$. After a repeated PBS wash and $2 \mathrm{~h}$ of incubation with $12 \mathrm{mM}$ MTT (Thermo Fisher Scientific, Hillsboro, OR, USA) dissolved in phenol red-free DMEM. Formazan crystals were dissolved in dimethyl sulfoxide and absorbance at $540 \mathrm{~nm}$ was measured.

\subsection{Cytokine Assay}

To assess cytokine production of RAW264.7 cells, ELISA assays were applied (R\&D systems, Minneapolis, MN, USA). For these experiments, $4 \times 10^{5}$ RAW264.7 cells were seeded in 6-well plates and incubated for $24 \mathrm{~h}$ followed by $24 \mathrm{~h}$ starvation. Afterwards, the cells were treated with $50 \mu \mathrm{g} / \mathrm{mL}$ EV for $4 \mathrm{~h}$, washed in PBS, and then stimulated with LPS for $18 \mathrm{~h}$. Cell culture supernatant was collected and used for IL-6 ELISA. The RAW264.7 cells were lysed with radioimmunoprecipitation assay (RIPA) buffer and the cell lysate was used for Western blots and IL-1 $\beta$ ELISA. The ELISA assays were performed according to the manufacturer's protocol and absorbance was measured at $450 \mathrm{~nm}$.

\subsection{Western Blotting}

Protein from the pooled EV samples was separated on $18 \%$ protogels and transferred onto a polyvinylidene difluoride membrane by electroblotting ( $60 \mathrm{~min}$ at $200 \mathrm{~V}$ and $500 \mathrm{~mA}$ ). Membranes were blocked in $2 \%$ Tween-20 in TBS-T buffer ( $50 \mathrm{mM}$ Tris, $0.5 \mathrm{M} \mathrm{NaCl}, \mathrm{pH}$ 7.4) prior to incubation with primary $\mathrm{AB} C \mathrm{CD} 81$, lactadherin or $\beta$-casein overnight at $4{ }^{\circ} \mathrm{C}$. Afterwards, the membranes incubated with a secondary AB for $1 \mathrm{~h}$ at RT before the membranes were washed and developed with an alkaline phosphatase reaction.

To collect cell lysates, RAW264.7 cells were lysed with ice-cold RIPA assay buffer and incubated $5 \mathrm{~min}$ on ice. The total cell lysate was centrifuged at $8000 \times g$ for $10 \mathrm{~min}$ at $4{ }^{\circ} \mathrm{C}$ and protein concentration in the supernatant was determined with a BCA protein determination kit (Thermo Scientific, Rockford, IL, USA). For Western blots, equal amounts of cell lysates ( $50 \mu \mathrm{g}$ protein/well) were resolved by 18\% SDS-PAGE and blotted onto a polyvinylidene fluoride (PVDF) membrane by electroblotting (IBlot ${ }^{\mathrm{tm}}$ Invitrogen, Carlsbad, CA, USA) and blocked in $2 \%$ Tween-20 TBS buffer. The membrane incubated with primary $\mathrm{AB} I \kappa \mathrm{B} \alpha$ or $\beta$-actin (both diluted 1:1000) at $4{ }^{\circ} \mathrm{C}$ overnight and secondary HRP-conjugated 
$\mathrm{AB}$ for $1 \mathrm{~h}$ at RT. The membrane was developed by an Image Quant Las 4000 with Enhanced Chemiluminescence Western blotting detection reagent (GE Healthcare, Loughborough, UK). Quantification of Western blots was performed in ImageJ with data normalized to $\beta$-actin.

\subsection{Statistics}

To detect if there were statistically significant differences on cell viability, cytokine secretion, or Western blots with IкB $\alpha$ between the control and one of the EV treatments of RAW264.7 cells, Student's $t$-tests were performed using MS Excel. Data are presented as mean \pm standard deviation. Statistical significance was set to $p$-value $<0.05$ compared to the given control.

\section{Results}

\subsection{Detection of CD81 in Extracellular Vesicles Isolates}

Extracellular vesicles were isolated using centrifugation and size exclusion chromatography (SEC) from milk and dairy fractions; raw unprocessed bovine milk (bEV), raw unprocessed colostrum milk (cEV), and wet and dry phospholipid enriched fractions using both a whey protein concentrate $(\mathrm{wEV})$ and a micellar casein isolate $(\mathrm{mcEV})$ as source material (Table 1). The EV isolation procedure has been described and verified in detail previously [29], and all characteristics were in accordance with previously conducted EV separations from human and bovine milk. To confirm the presence of milk EVs in the isolates, Western blots against the classical EV biomarker CD81 were made [33]. Figure 1 shows that all bovine EV isolates were CD81-positive. Proteoliposomes also showed a weak band for CD81, which implies a minor presence of EV remnants in the used membrane protein fraction. Anyhow, the proteoliposomes were still considered as a valid control for milk EVs. Details about the conducted EV separations are given in the (Supplementary Materials Figures S1 and S2).

Table 1. Overview of abbreviations for EVs used in this study. A: EV isolation made from raw unprocessed milk. ${ }^{\mathrm{B}}$ : two EV isolations were made from fractions before and after drying, referred to as the "wet" or "dry" EV isolate, respectively.

\begin{tabular}{cc}
\hline EV Source & Abbreviation \\
\hline Bovine milk & $\mathrm{bEV}^{\mathrm{A}}$ \\
\hline Bovine colostrum & $\mathrm{cEV}^{\mathrm{A}}$ \\
\hline Human breast milk & $\mathrm{hEV}^{\mathrm{A}}$ \\
\hline Whey protein concentrate-Phospholipid enriched & $\mathrm{wEV}^{\mathrm{B}}$ \\
\hline Micellar Casein Isolate-Phospholipid enriched & $\mathrm{mcEV}^{\mathrm{B}}$ \\
\hline Proteoliposomes & ProLip \\
\hline
\end{tabular}

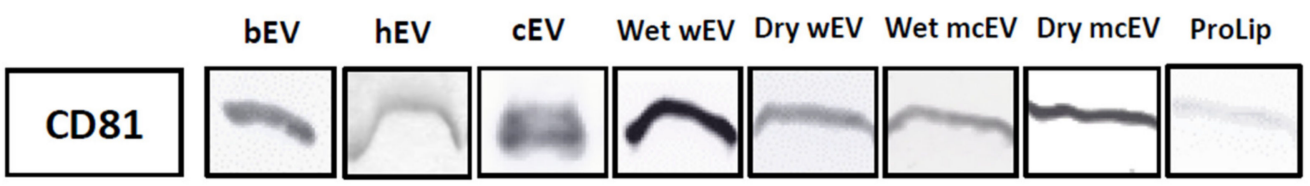

Figure 1. CD81 Western blot of EV isolates. Western blots were conducted on aliquots of pools from the individual EV isolations using a Sephacryl S-500 SEC column (for chromatograms see Supplementary Figures S1 and S2). Six $\mu$ g of each EV isolate were separated on an 18\% SDS-PAGE, transferred to a PVDF membrane and probed for CD81, a classical EV surface marker. Eight $\mu$ g of proteoliposomes (ProLip) were used for the Western blot. 


\subsection{Uptake of Extracellular Vesicles in RAW264.7 Cells}

Uptake studies were performed to evaluate whether there was a dose- or timedependent uptake of bEVs. The cells were stimulated with either $10 \mu \mathrm{g} / \mathrm{mL}$ or $50 \mu \mathrm{g} / \mathrm{mL}$ $\mathrm{bEVs}$ for $0-24 \mathrm{~h}$. Figure 2 shows an increase in the fluorescent signal depending on the bEV concentration, with the higher bEV dose resulting in a higher signal. It was observed that a maximum bEV uptake was reached after $18 \mathrm{~h}$ with both bEV concentrations. Up to $4 \mathrm{~h}$ of incubation with $50 \mu \mathrm{g} / \mathrm{mL}$ of bEV, the RAW264.7 cells showed a rapid increase in bEV uptake. These results indicated that $4 \mathrm{~h}$ of incubation with $50 \mu \mathrm{g} / \mathrm{mL}$ of bEV protein was sufficient time for RAW264.7 cells to take up the bEVs.

a)

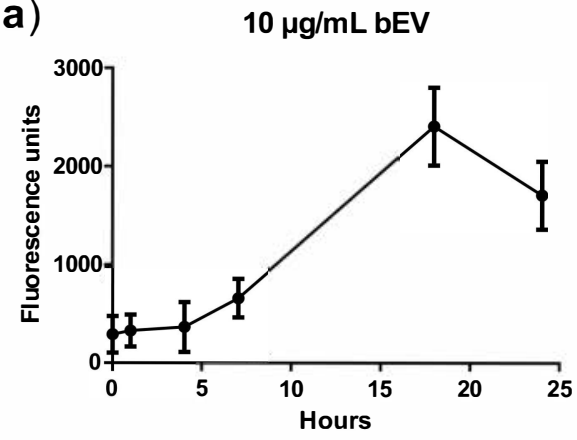

b)

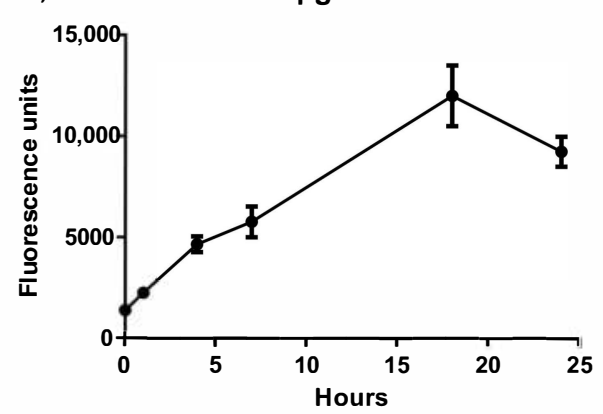

Figure 2. Bovine extracellular vesicles uptake in RAW264.7 cells. To detect bEV uptake, RAW264.7 cells incubated with either (a) $10 \mu \mathrm{g} / \mathrm{mL}$ or (b) $50 \mu \mathrm{g} / \mathrm{mL}$ of fluorescently labelled bEVs for $1,4,7,18$, or $24 \mathrm{~h}$. Afterwards, the fluorescence of the resulting cell lysate was quantified. The values are shown as mean \pm SD. Two independent experiments were performed in triplicates. Background fluorescence from the lysis buffer was subtracted from the results. See Table 1 for sample nomenclature.

\subsection{Effect of Extracellular Vesicle Incubation on RAW264.7 Cell Viability}

The potential cytotoxicity of the different EV isolates on RAW264.7 cells was analyzed by an MTT viability assay. Figure 3 shows that the EV treatments did not affect RAW264.7 cell viability after $4 \mathrm{~h}$ of incubation. Treatment with bEV and cEV increased survival significantly compared to the control (proteoliposomes). Treatment with high amounts $(100 \mu \mathrm{g} / \mathrm{mL})$ of wet mcEV resulted in the lowest cell survival, whereas the lower doses of wet mcEV had no effect on cell viability. All other EV samples showed no significant change in viability as response to $\mathrm{EV}$ incubation for $4 \mathrm{~h}$.

\subsection{Immunoregulating Effects of Extracellular Vesicles on RAW264.7 Cells}

Bioactivity was investigated on LPS-stimulated RAW264.7 cells by preincubation with the different EV isolates, followed by investigation of a possibly altered immune reaction as response to LPS stimulation. Cytokine production and the NF- $\mathrm{KB}$ pathway was investigated by ELISA or Western blotting, respectively. Figure 4 shows the experimental procedure. 


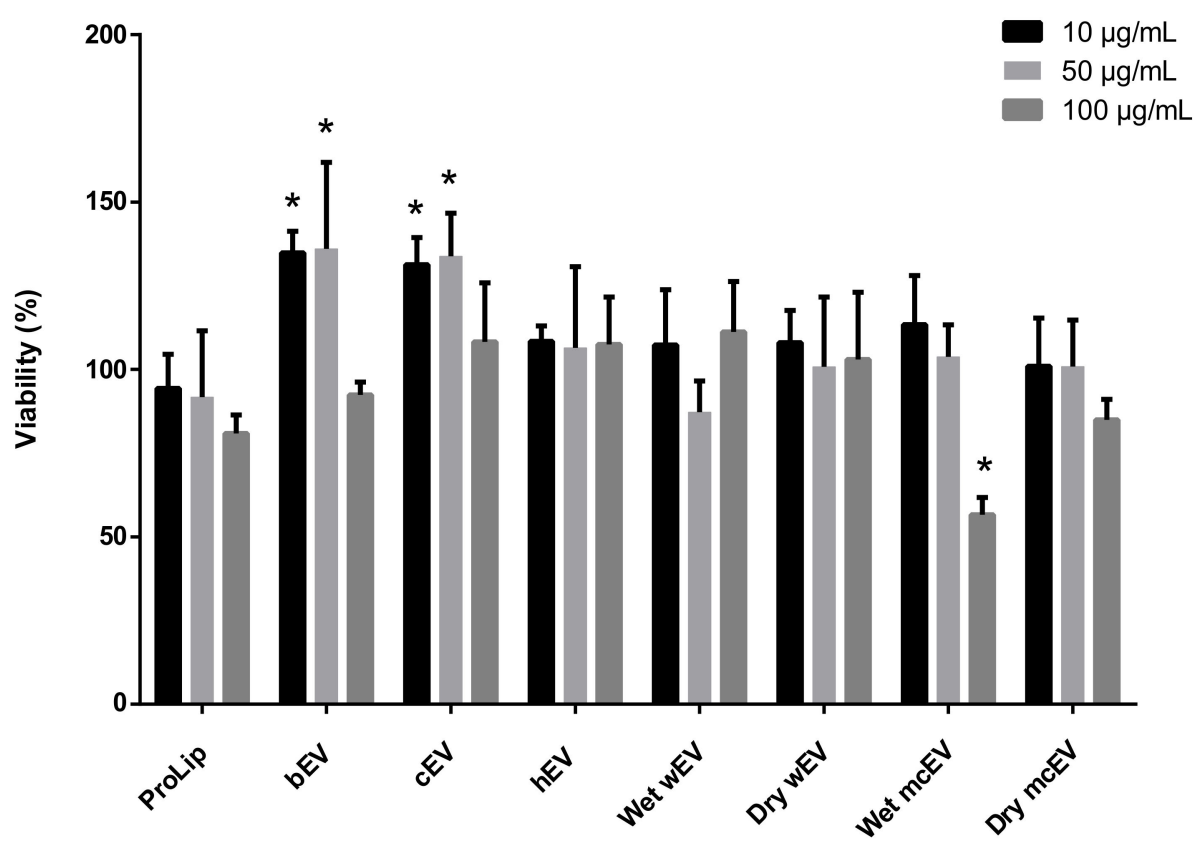

Figure 3. Cell viability after incubation with EV isolates assessed with an MTT assay. RAW264.7 cells incubated for $4 \mathrm{~h}$ with $10 \mu \mathrm{g} / \mathrm{mL}, 50 \mu \mathrm{g} / \mathrm{mL}$, or $100 \mu \mathrm{g} / \mathrm{mL}$ of EV protein. The values are calculated from non EV-treated cells grown simultaneously with the EV-treated cells (results not shown). Representative data are presented as means \pm SD of four replicas, a minimum of two independent experiments were performed. Differences between control treatment (proteoliposomes, ProLip) and EV treatment were assessed by Student's $t$-test. *: $p$-value $<0.05$ vs. the corresponding ProLip treatment. See Table 1 for sample nomenclature.

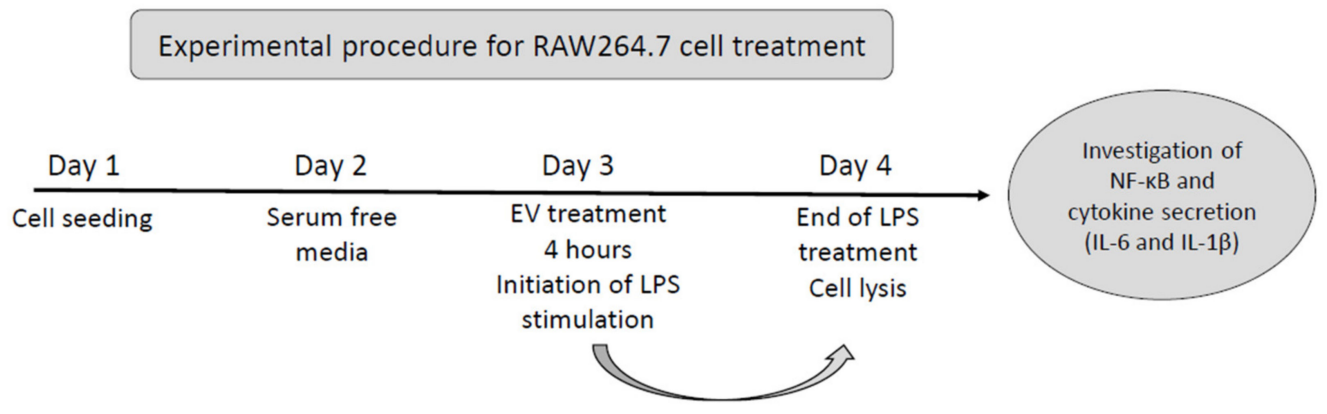

Figure 4. Experimental procedure for cell experiments. Initially, RAW264.7 cells were seeded in a 6-well plate and starved for $24 \mathrm{~h}$ to avoid effects of serum constituents before EV treatment for $4 \mathrm{~h}$, followed by $18 \mathrm{~h}$ of LPS stimulation. Cell culture supernatant and cell lysate were harvested and used for IKB $\alpha$ Western blots and cytokine assays.

\subsection{Preincubation with EVs Alter Activation of the NF- $\kappa B$ Pathway}

To investigate activation of the NF- $\kappa B$ pathway in RAW264.7 cells as response to LPS treatment, degradation of $\mathrm{I} \kappa \mathrm{B} \alpha$ was investigated. Cells with an active NF- $\kappa \mathrm{B}$ pathway degraded $I \kappa B \alpha$, as observed in the control (Figure 5a). Quantifications of the Western blots are shown in Figure $5 b$. It shows fold change in the I $\mathrm{B} \mathrm{B} \alpha$ level (non-LPS-treated/LPStreated cells), thereby showing the difference in activation of the NF-kB pathway. RAW264.7 cells pre-treated with $\mathrm{bEV}$ or hEV showed no change in $\mathrm{I} \kappa \mathrm{B} \alpha$ level after treatment with LPS, and these treatments resulted in a significantly lower activation of the NF- $\mathrm{B}$ pathway 
compared to the control. Treatment with cEV or wet wEV did not result in a statistically significant decrease in IkB $\alpha$ degradation compared to the control.
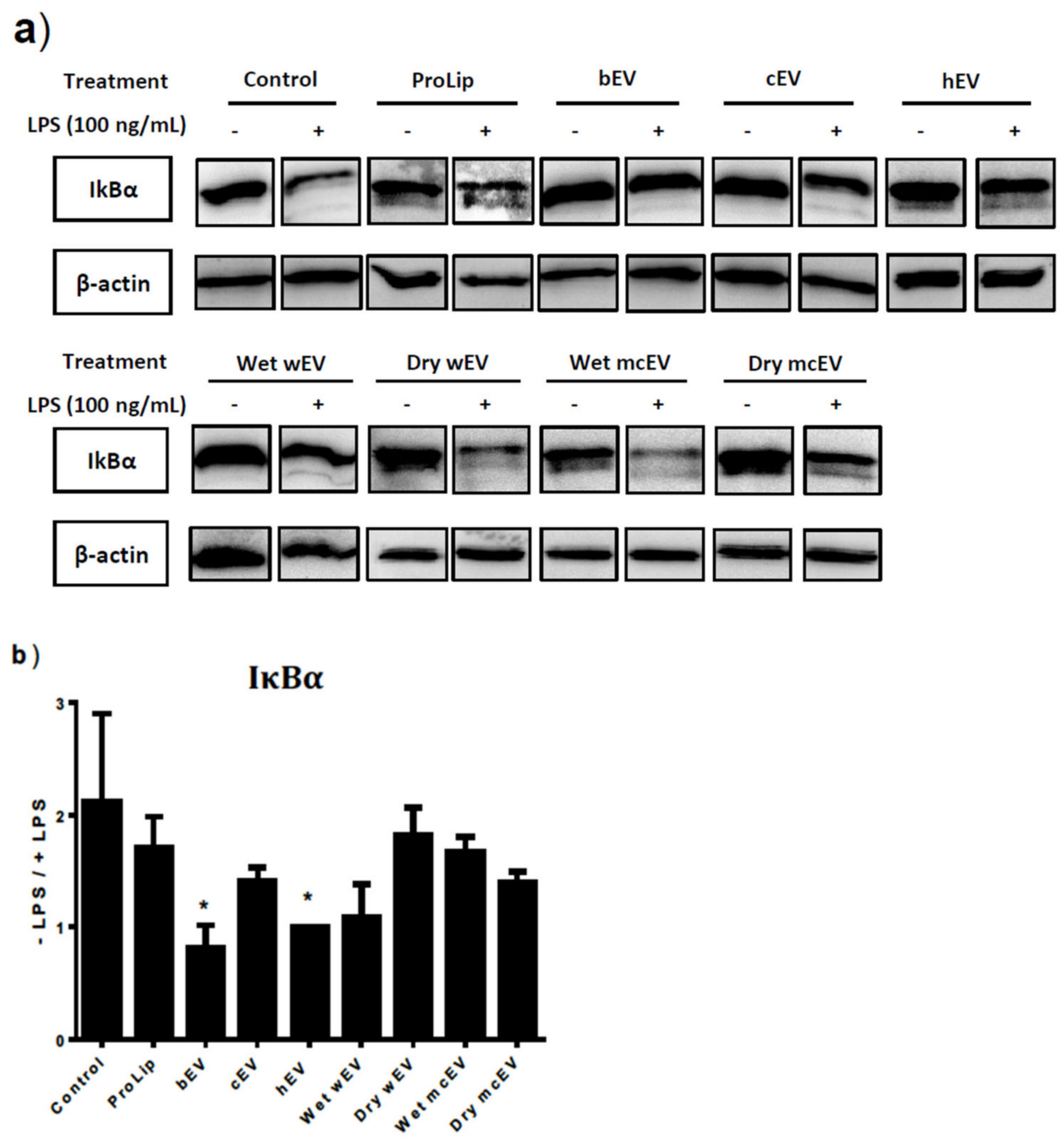

Figure 5. Evaluation of NF- $\mathrm{kB}$ pathway activation. (a) Western blots were carefully loaded with RAW264.7 cell lysates (50 $\mathrm{mg}$ protein/well) after treatment with the given EV isolate or control followed by LPS stimulation. $\beta$-actin was used as loading control to normalize data. The original Western blots can be seen in Figure S3. (b) Quantification of the bands shown in Figure 5a, depicted as a ratio between non-LPS-treated cells/LPS-treated RAW264.7 cells. The bands were quantified using ImageJ. All ratios were compared to the control by a Student's $t$-test. ${ }^{*} p$-value $<0.05$ vs. the control. The results were obtained by a minimum of two independent experiments. See Table 1 for sample nomenclature.

\subsection{Preincubation with EVs Alter Cytokine Secretion from RAW264.7 Cells}

RAW264.7 cells' production of cytokines as response to LPS stimulation was measured after preincubation with the different EV isolates. All EV treatments, including the proteoliposome control, resulted in significantly less secretion of the proinflammatory cytokine IL-6 in LPS-stimulated RAW264.7 cells (Figure 6a). The largest reduction was seen after preincubation with $\mathrm{bEV}$ and wet $\mathrm{wEV}$. The amount of the proinflammatory cytokine, IL-1 $\beta$, produced by EV-preincubated LPS-stimulated RAW264.7 cells is shown in Figure 6b. The same tendency is observed here: all EV treatments resulted in a lower production of cytokine with a significant difference from the control. LPS-stimulated RAW264.7 cell preincubated with proteoliposomes did not result in a statistically significant reduction of IL-1 $\beta$ production. 

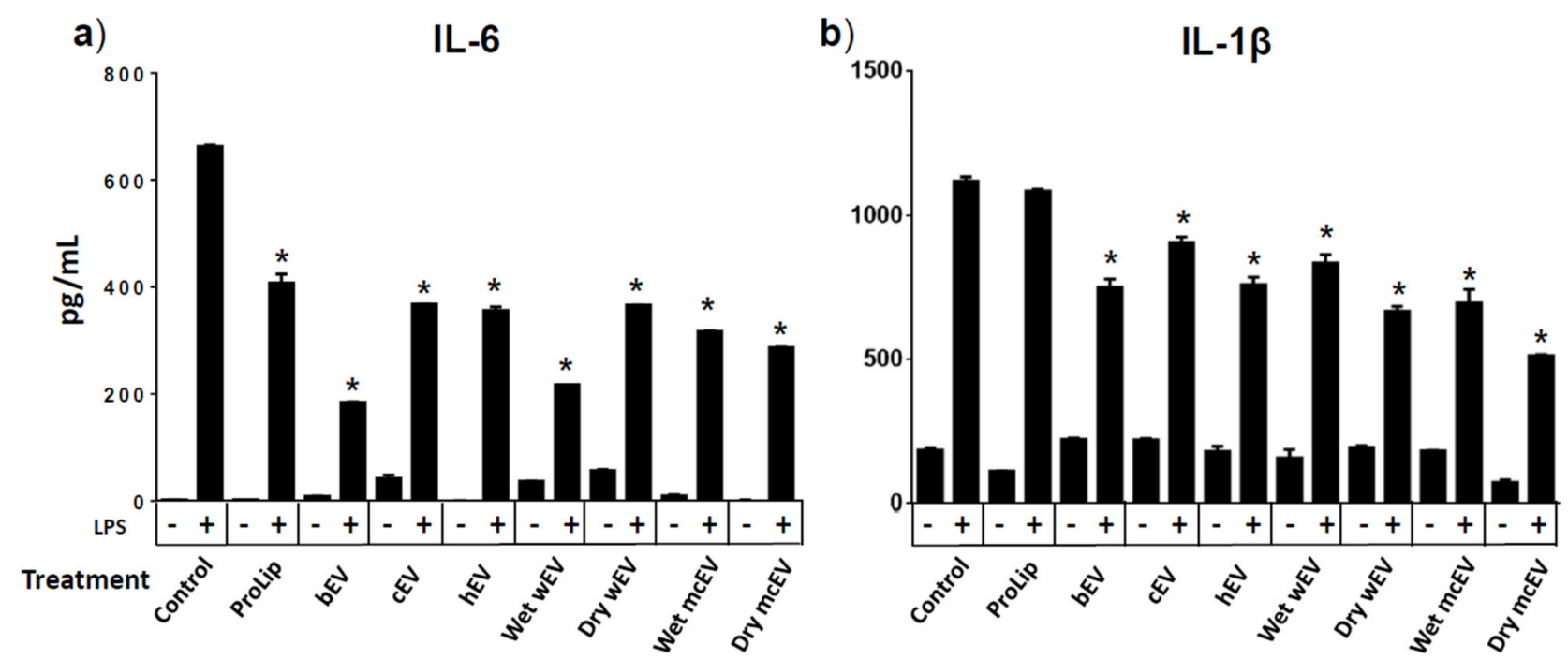

Figure 6. Cytokine ELISA assay. LPS-stimulated RAW264.7 cells were pre-treated with EV isolates from bovine or human mature milk, bovine colostrum, WPC-PL, or MCI-PL. Afterwards, cell culture supernatants were used for (a) IL-6 ELISA and cell lysates were used for (b) IL-1 $\beta$ ELISA cytokine assay. A minimum of two independent cell experiments were performed for each EV treatment. Cytokine concentration in each sample was calculated from a standard curve made with each individual experiment. Student's $t$-test was performed comparing each EV + LPS-treated sample to the LPS-treated control. * $p$-value $<0.05$ vs. the control. See Table 1 for sample nomenclature.

\section{Discussion}

Since the discovery of EVs in breastmilk in 2007 [12], several studies have tried to clarify the role of these EVs in relation to mother-to-infant communication and what effects the EVs and their cargo have on an infant's developing immune system [2,4,8]. In the present study, immune-regulating properties of EVs isolated from a variety of dairy fractions were evaluated using the murine cell line RAW264.7. By fluorescent labelling of bEVs, it was shown that RAW264.7 cells could take up bEVs $(50 \mu \mathrm{g} / \mathrm{mL})$ after $4 \mathrm{~h}$ of incubation without negatively affecting the cell viability. Additionally, inflammatory activity was evaluated with cytokine expression analysis and activation of the NF- $\mathrm{kB}$ pathway on LPS-stimulated RAW264.7 cells pre-treated with the different EV isolates (see Table 1).

Treatment with both bovine EVs (bEV) or human EVs (hEV) was able to adverse the degradation of $I \kappa B \alpha$, which is seen in the LPS-activated NF- $\kappa B$ pathway. Additionally, all the tested milk and milk fraction EV isolates were able to significantly reduce the amount of produced IL- 6 and IL- $1 \beta$ by LPS-stimulated RAW 264.7 cells compared to the control receiving no EVs. In total, the presented results show that EV isolates from bovine and human milk and a variety of milk samples possess the ability to change immunological responses induced by LPS without negatively affecting cell viability.

Bovine milk-derived EVs are currently being considered a possible drug delivery system [5], yet for bEVs to be used as such they must be biocompatible and cannot show any immunotoxicity. Somiya and coworkers (2018) found no cytotoxic effects of bEVs on RAW264.7 cells, which agrees with the absence of EV-induced biotoxicity presented in this study. In total, these data indicate that the tested EV isolates and in the tested doses hereof could serve as safe drug delivery systems. Additionally, it was observed that the RAW264.7 cells were able to internalize bEVs (Figure 2), which is in agreement with uptake studies made with a variety of cell lines from different species, including bone marrow-derived mesenchymal stroma cells [34,35], mouse macrophages (RAW264.7) [5,8], human intestinal epithelial cells (Caco-2) [11], lung (A549) and colon (HCT116) cancer cell lines [36]. More detailed studies are needed to establish whether the applied EVs are internalized by the conventional endocytic endosomal pathway in RAW264.7 cells as seen for Caco-2 cells 
(Hansen et al. 2020). A study by Wolf et al. used Caco-2 cells to show bEV uptake after $2 \mathrm{~h}$ of incubation [10], and in the present study, bEVs $(50 \mu \mathrm{g} / \mathrm{mL})$ were internalized by RAW264.7 cells after $4 \mathrm{~h}$. Thus, it does not appear that long incubation times are necessary for a cellular uptake of bEVs.

To assess possible immune-regulating properties of isolated dairy EVs, RAW264.7 cells were primed with an EV isolate prior to LPS stimulation. LPS is recognized by TLR4 on the surface of resident macrophages, which intracellularly activates the NF- $\kappa B$ pathway. NF- $\kappa B$ exists in an inactive form in the cytoplasm, bound to its inhibitor IkB. When the pathway is activated, IkB is degraded and the released NF- $k B$ translocates to the nuclei, where it initiates proinflammatory cytokine production [16,37]. Cellular response was investigated on an intracellular level by looking at degradation of $\operatorname{IkB} \alpha$ (Figure 5), which follows the activation level of the NF-kB pathway [38]. In some pathological cases, this pathway can be overstimulated, leading to chronic inflammatory diseases, such as inflammatory bowel disease, arthritis, or Crohn's disease [39-41]. To avoid development of such diseases, the pathway must be tightly regulated. This is also the case with infants, where the immune system is still under development and therefore vulnerable to cellular dysregulations [22].

Figure 5 shows how pre-treatment with $\mathrm{bEV}, \mathrm{cEV}, \mathrm{hEV}, \mathrm{wEV}$, and mcEV might contribute to such inflammatory regulation in RAW264.7 cells. It was observed that all these EV treatments downregulated the LPS-induced inflammatory response in RAW264.7 cells. Yet, the mechanism behind this downregulation needs further investigation and other parts of the NF-кB pathway may be involved. Additionally, proteoliposomes did not seem to have any effect on the cellular response, supporting the theory that the cargo/miRNA of EVs is important for the cell-to-cell communication [2,3].

RAW264.7 cell cytokine release was also investigated after priming with EV isolates prior to LPS stimulation. These results showed a downregulation of the inflammatory cytokines IL-6 and IL-1 $\beta$ compared to the control. Studies with milk phospholipid membrane components has shown to protect against early life infections [42]. Aziz and coworkers showed that LPS-stimulated RAW264.7 cells pretreated with recombinant lactadherin (another milk protein) had a significant decrease in TNF- $\alpha$ production [43]. Thus, the EV membrane with its protein and phospholipid components may influence the macrophages' cytokine secretion by itself. This matter will be revealed by future experiments. Importantly, no cytokine release was seen in response to EV treatment alone, confirming that the EVs did not induce cytokine secretion on their own.

The composition of EVs includes multiple types of molecules such as a variety of proteins, phospholipids, and miRNA. Biological activities regulated by EVs are therefore likely to be a combination of actions provided in concert by EV components. Studies have found miRNAs from milk-derived exosomes involved in the regulation of immune responses, providing a possible explanation for the immune response in EV-treated vs. nontreated RAW264.7 cells [44,45]. Differences in the EV cargo might also be a part of the explanation why some EVs (bEV) have a greater effect on the RAW264.7 cells' cytokine secretion than others (cEV) in the presented study (Figure 6). MiRNAs found in bEVs, like miR-141 or miR-155, have been shown to downregulate the production of proinflammatory cytokines, by suppressing the activation of the NF-kB leading to a decreased level of inflammation in the intestine [46-48]. These studies, together with the results presented in this study, indicate that EVs in milk and dairy samples contribute to keeping the gut in homeostasis and a low level of inflammation in the gut of newborn infants.

Newborn infants need immunological protection when encountering the extrauterine life. For that reason, colostrum has a different composition than mature milk [13]. For example, colostrum contains high amounts of immunoglobulins, which provide additional immunological protection $[49,50]$. This fact has raised another question: could colostrum EVs be different from EVs found in mature milk? A study made by Sun et al. (2013) showed that preincubating LPS-stimulated RAW264.7 cells with cEVs had an upregulating effect on IL- 6 and IL-1 $\beta$ cytokine secretion compared with incubation with bEVs. Yet, the present study shows the opposite tendency, with bEVs being more effective in downregulating 
the level of IL-6 and IL-1 $\beta$ compared with cEVs (Figure 6). An explanation may be the classification of colostrum versus mature milk. The mature milk used in this study was freshly collected from a big tank with a mixture of bovine milk from different lactation stages. The colostrum was from one cow two days postpartum. The colostrum that Sun et al. used was from a cow 7 days postpartum and the mature milk was obtained 9 months into lactation. Hence, the different observations between the studies might be a consequence hereof. A study from 2019 shows that colostrum has the greatest effect on immunity within the first 16-27 h of a newborn calf's life [49]. For now, the findings of the current study reject the idea that cEVs should be more effective in providing immunological protection than bEVs.

The question remains, whether the decreased inflammatory response as a consequence of EV preincubation reported in the current study produced a faster LPS response in RAW264.7 cells or whether the EVs downregulated the production of cytokines during the entire period of an inflammatory response. Kinetic experiments of cytokine detection and further investigation of the activation of the NF-kB pathway could be valuable knowledge regarding the underlying molecular mechanism for the observed anti-inflammatory response. The effects of EVs on macrophages' immune response reported in this study indicate that $\mathrm{EV}$ isolates from breastmilk (hEV) and from infant formula (bEV, $\mathrm{wEV}, \mathrm{mcEV}$ ) affect the developing immune system of infants.

The anti-inflammatory responses in RAW264.7 cells as a consequence of bEV and wEV treatment open an opportunity to possibly use these EV isolates in future treatment of patients with chronic inflammatory diseases in the gut [39,46]. Overall, the data presented in this study, using a diverse range of EV isolates, show that these may constitute part of the maintenance of gut homeostasis in infants by keeping the level of inflammation low [22]. The EVs isolated from raw bovine milk may work as an improvement to infant formula in the future. Yet, the complete underlying molecular mechanisms for this immune response in RAW264.7 cells have yet to be discovered.

\section{Conclusions}

The present study showed that EVs derived from bovine milk, human milk, whey, and skim milk products, used for pre-treatment of LPS-stimulated RAW264.7 cells, resulted in a reduced inflammatory response. Especially incubation with bEVs and $\mathrm{hEV}$ reduced the degradation of $I \kappa B \alpha$, indicating a downregulation of inflammation in RAW264.7 cells. Additionally, it was found that bEV, cEVs, hEVs, and dairy whey or skim milk-derived EVs were bioactive and able to downregulate cytokine secretion from LPS-stimulated RAW264.7 cells. These results highlight the importance of preparing dairy products as gentle as possible. All together, these investigations provide further knowledge about the biological activities of milk-derived EVs, which is valuable for further investigations regarding milk EVs in infant nutrition and health.

Supplementary Materials: The following are available online at https://www.mdpi.com/2624-862 X/2/2/15/s1, Figure S1: Analysis of EV isolations, Figure S2: Analysis of EV isolation from wet and dry WPC-PL and MCI-PL, Figure S3: Total western blots used in Figure 5.

Author Contributions: Conceptualization, S.R.A., M.S.H., M.S.O. and J.T.R.; data curation, S.R.A.; formal analysis, S.R.A.; investigation, S.R.A.; methodology, S.R.A., M.S.H., M.S.O. and J.T.R.; validation, S.R.A.; writing—original draft, S.R.A.; writing—review and editing, S.R.A., M.S.H., M.S.O. and J.T.R. All authors have read and agreed to the published version of the manuscript.

Funding: The work was supported by The Milk Levy Fund (Aarhus N, Denmark), Aarhus University, and Arla Foods Ingredients P/S (Viby, Denmark).

Institutional Review Board Statement: Not applicable.

Informed Consent Statement: Not applicable.

Data Availability Statement: The data presented in this study are available on request from the corresponding author. 
Acknowledgments: We are grateful to Anni Bojsen for technical support and thankful to the mothers who donated milk.

Conflicts of Interest: The authors declare no conflict of interest. The funders had no role in the design of the study; in the collection, analyses, or interpretation of data; in the writing of the manuscript, or in the decision to publish the results.

\section{References}

1. Abels, E.R.; Breakefield, X.O. Introduction to Extracellular Vesicles: Biogenesis, RNA Cargo Selection, Content, Release, and Uptake. Cell. Mol. Neurobiol. 2016, 36, 301-312. [CrossRef] [PubMed]

2. Lonnerdal, B. Human Milk MicroRNAs/Exosomes: Composition and Biological Effects. Nestle Nutr. Inst. Workshop Ser. 2019, 90, 83-92. [CrossRef] [PubMed]

3. Zempleni, J.; Aguilar-Lozano, A.; Sadri, M.; Sukreet, S.; Manca, S.; Wu, D.; Zhou, F.; Mutai, E. Biological Activities of Extracellular Vesicles and Their Cargos from Bovine and Human Milk in Humans and Implications for Infants. J. Nutr. 2017, 147, 3-10. [CrossRef]

4. de la Torre Gomez, C.; Goreham, R.V.; Bech Serra, J.J.; Nann, T.; Kussmann, M. “Exosomics"-A Review of Biophysics, Biology and Biochemistry of Exosomes With a Focus on Human Breast Milk. Front. Genet. 2018, 9, 92. [CrossRef] [PubMed]

5. Somiya, M.; Yoshioka, Y.; Ochiya, T. Biocompatibility of highly purified bovine milk-derived extracellular vesicles. J. Extracell Vesicles 2018, 7, 1440132. [CrossRef]

6. Golan-Gerstl, R.; Elbaum Shiff, Y.; Moshayoff, V.; Schecter, D.; Leshkowitz, D.; Reif, S. Characterization and biological function of milk-derived miRNAs. Mol. Nutr. Food Res. 2017, 61, 1700009. [CrossRef] [PubMed]

7. Leiferman, A.; Shu, J.; Upadhyaya, B.; Cui, J.; Zempleni, J. Storage of Extracellular Vesicles in Human Milk, and MicroRNA Profiles in Human Milk Exosomes and Infant Formulas. J. Pediatr. Gastroenterol. Nutr. 2019, 69, 235-238. [CrossRef] [PubMed]

8. Sun, Q.; Chen, X.; Yu, J.; Zen, K.; Zhang, C.Y.; Li, L. Immune modulatory function of abundant immune-related microRNAs in microvesicles from bovine colostrum. Protein Cell 2013, 4, 197-210. [CrossRef] [PubMed]

9. Liao, Y.; Du, X.; Li, J.; Lonnerdal, B. Human milk exosomes and their microRNAs survive digestion in vitro and are taken up by human intestinal cells. Mol. Nutr. Food Res. 2017, 61, 1700082. [CrossRef] [PubMed]

10. Wolf, T.; Baier, S.R.; Zempleni, J. The Intestinal Transport of Bovine Milk Exosomes Is Mediated by Endocytosis in Human Colon Carcinoma Caco-2 Cells and Rat Small Intestinal IEC-6 Cells. J. Nutr. 2015, 145, 2201-2206. [CrossRef]

11. Hansen, M.S.; Gadegaard, I.S.E.; Arnspang, E.C.; Blans, K.; Nejsum, L.N.; Rasmussen, J.T. Specific and Non-Invasive Fluorescent Labelling of Extracellular Vesicles for Evaluation of Intracellular Processing by Intestinal Epithelial Cells. Biomedicines $2020,8,211$. [CrossRef] [PubMed]

12. Admyre, C.; Johansson, S.M.; Qazi, K.R.; Filen, J.J.; Lahesmaa, R.; Norman, M.; Neve, E.P.; Scheynius, A.; Gabrielsson, S. Exosomes with immune modulatory features are present in human breast milk. J. Immunol. 2007, 179, 1969-1978. [CrossRef] [PubMed]

13. Chatterton, D.E.; Nguyen, D.N.; Bering, S.B.; Sangild, P.T. Anti-inflammatory mechanisms of bioactive milk proteins in the intestine of newborns. Int. J. Biochem. Cell Biol. 2013, 45, 1730-1747. [CrossRef]

14. Chassaing, B.; Kumar, M.; Baker, M.T.; Singh, V.; Vijay-Kumar, M. Mammalian gut immunity. Biomed. J. 2014, 37, 246-258. [CrossRef] [PubMed]

15. Mowat, A.M.; Bain, C.C. Mucosal Macrophages in Intestinal Homeostasis and Inflammation. J. Innate Immun. 2011, 3, 550-564. [CrossRef] [PubMed]

16. Grainger, J.R.; Konkel, J.E.; Zangerle-Murray, T.; Shaw, T.N. Macrophages in gastrointestinal homeostasis and inflammation. Pflug. Arch. Eur. J. Physiol. 2017, 469, 527-539. [CrossRef] [PubMed]

17. Hirano, S.; Zhou, Q.; Furuyama, A.; Kanno, S. Differential Regulation of IL-1beta and IL-6 Release in Murine Macrophages. Inflammation 2017, 40, 1933-1943. [CrossRef] [PubMed]

18. Zhang, W.; Yan, J.; Wu, L.; Yu, Y.; Ye, R.D.; Zhang, Y.; Liang, X. In vitro immunomodulatory effects of human milk oligosaccharides on murine macrophage RAW264.7 cells. Carbohydr. Polym. 2019, 207, 230-238. [CrossRef] [PubMed]

19. Huang, T.C.; Kuksis, A. A comparative study of the lipids of globule membrane and fat core and of the milk serum of cows. Lipids 1967, 2, 453-460. [CrossRef]

20. Heid, H.W.; Keenan, T.W. Intracellular origin and secretion of milk fat globules. Eur. J. Cell Biol. 2005, 84, 245-258. [CrossRef]

21. Rasmussen, J.T. Bioactivity of milk fat globule membrane proteins. Aust. J. Dairy Technol. 2009, 64, 63-67.

22. Laouar, A. Maternal Leukocytes and Infant Immune Programming during Breastfeeding. Trends Immunol. 2020, 41, 225-239. [CrossRef] [PubMed]

23. Hettinga, K.; van Valenberg, H.; de Vries, S.; Boeren, S.; van Hooijdonk, T.; van Arendonk, J.; Vervoort, J. The host defense proteome of human and bovine milk. PLoS ONE 2011, 6, e19433. [CrossRef] [PubMed]

24. Yu, J.C.; Khodadadi, H.; Malik, A.; Davidson, B.; Salles, E.; Bhatia, J.; Hale, V.L.; Baban, B. Innate Immunity of Neonates and Infants. Front. Immunol. 2018, 9, 1759. [CrossRef]

25. Hobbs, S.; Reynoso, M.; Geddis, A.V.; Mitrophanov, A.Y.; Matheny, R.W., Jr. LPS-stimulated NF-kappaB p65 dynamic response marks the initiation of TNF expression and transition to IL-10 expression in RAW 264.7 macrophages. Physiol. Rep. 2018, 6, e13914. [CrossRef] 
26. Jeong, Y.H.; Oh, Y.C.; Cho, W.K.; Yim, N.H.; Ma, J.Y. Hoveniae Semen Seu Fructus Ethanol Extract Exhibits Anti-Inflammatory Activity via MAPK, AP-1, and STAT Signaling Pathways in LPS-Stimulated RAW 264.7 and Mouse Peritoneal Macrophages. Mediat. Inflamm. 2019, 2019, 9184769. [CrossRef] [PubMed]

27. Choi, Y.H.; Kang, H.J. Fructus sophorae attenuates secretion of proinflammatory mediators and cytokines through the modulation of NF-kappaB and MAPK signaling pathways in LPS-stimulated RAW 264.7 macrophages. Gen. Physiol. Biophys. 2016, 35, 323-331. [CrossRef] [PubMed]

28. Park, J.C.; Yoo, H.; Kim, C.E.; Shim, S.Y.; Lee, M. Hispidulin-7-O-Neohesperidoside from Cirsium japonicum var. ussuriense Attenuates the Production of Inflammatory Mediators in LPS-Induced Raw 264.7 Cells and HT-29 Cells. Pharmacogn. Mag. 2017, 13, 707-711. [CrossRef]

29. Blans, K.; Hansen, M.S.; Sorensen, L.V.; Hvam, M.L.; Howard, K.A.; Moller, A.; Wiking, L.; Larsen, L.B.; Rasmussen, J.T. Pellet-free isolation of human and bovine milk extracellular vesicles by size-exclusion chromatography. J. Extracell Vesicles 2017, 6, 1294340. [CrossRef]

30. Hvarregaard, J.; Andersen, M.H.; Berglund, L.; Rasmussen, J.T.; Petersen, T.E. Characterization of glycoprotein PAS-6/7 from membranes of bovine milk fat globules. Eur. J. Biochem. 1996, 240, 628-636. [CrossRef]

31. Lowry, O.H.; Rosebrough, N.J.; Farr, A.L.; Randall, R.J. Protein measurement with the Folin phenol reagent. J. Biol. Chem. 1951, 193, 265-275. [CrossRef]

32. Schacterle, G.R.; Pollack, R.L. A simplified method for the quantitative assay of small amounts of protein in biologic material. Anal. Biochem. 1973, 51, 654-655. [CrossRef]

33. Théry, C.; Witwer, K.W.; Aikawa, E.; Alcaraz, M.J.; Anderson, J.D.; Andriantsitohaina, R.; Antoniou, A.; Arab, T.; Archer, F.; Atkin-Smith, G.K.; et al. Minimal information for studies of extracellular vesicles 2018 (MISEV2018): A position statement of the International Society for Extracellular Vesicles and update of the MISEV2014 guidelines. J. Extracell. Vesicles 2018, 7, 1535750. [CrossRef]

34. Stahl, P.D.; Raposo, G. Extracellular Vesicles: Exosomes and Microvesicles, Integrators of Homeostasis. Physiology 2019, 34, 169-177. [CrossRef]

35. Tian, T.; Zhu, Y.L.; Zhou, Y.Y.; Liang, G.F.; Wang, Y.Y.; Hu, F.H.; Xiao, Z.D. Exosome uptake through clathrin-mediated endocytosis and macropinocytosis and mediating miR-21 delivery. J. Biol. Chem. 2014, 289, 22258-22267. [CrossRef] [PubMed]

36. Horibe, S.; Tanahashi, T.; Kawauchi, S.; Murakami, Y.; Rikitake, Y. Mechanism of recipient cell-dependent differences in exosome uptake. BMC Cancer 2018, 18, 47. [CrossRef] [PubMed]

37. Netea, M.G.; Balkwill, F.; Chonchol, M.; Cominelli, F.; Donath, M.Y.; Giamarellos-Bourboulis, E.J.; Golenbock, D.; Gresnigt, M.S.; Heneka, M.T.; Hoffman, H.M.; et al. A guiding map for inflammation. Nat. Immunol. 2017, 18, 826-831. [CrossRef]

38. Liu, T.; Zhang, L.; Joo, D.; Sun, S.-C. NF-кB signaling in inflammation. Signal Transduct. Target. 2017, 2, 17023. [CrossRef]

39. Shouval, D.S.; Biswas, A.; Goettel, J.A.; McCann, K.; Conaway, E.; Redhu, N.S.; Mascanfroni, I.D.; Al Adham, Z.; Lavoie, S.; Ibourk, M.; et al. Interleukin-10 receptor signaling in innate immune cells regulates mucosal immune tolerance and anti-inflammatory macrophage function. Immunity 2014, 40, 706-719. [CrossRef]

40. Rossi, J.F.; Lu, Z.Y.; Jourdan, M.; Klein, B. Interleukin-6 as a therapeutic target. Clin. Cancer Res. Off. J. Am. Assoc. Cancer Res. 2015, 21, 1248-1257. [CrossRef]

41. Chun, S.Y.; Lee, K.S.; Nam, K.S. Refined Deep-Sea Water Suppresses Inflammatory Responses via the MAPK/AP-1 and NF- $к B$ Signaling Pathway in LPS-Treated RAW 264.7 Macrophage Cells. Int. J. Mol. Sci. 2017, 18, 2282. [CrossRef]

42. Hernell, O.; Lonnerdal, B.; Timby, N. Milk Fat Globule Membranes: Effects on Microbiome, Metabolome, and Infections in Infants and Children. Nestle Nutr. Inst. Workshop Ser. 2020, 94, 133-140. [CrossRef]

43. Aziz, M.; Jacob, A.; Matsuda, A.; Wu, R.; Zhou, M.; Dong, W.; Yang, W.-L.; Wang, P. Pre-treatment of recombinant mouse MFG-E8 downregulates LPS-induced TNF- $\alpha$ production in macrophages via STAT3-mediated SOCS3 activation. PLoS ONE 2011, 6, e27685. [CrossRef]

44. Samuel, M.; Chisanga, D.; Liem, M.; Keerthikumar, S.; Anand, S.; Ang, C.S.; Adda, C.G.; Versteegen, E.; Jois, M.; Mathivanan, S. Bovine milk-derived exosomes from colostrum are enriched with proteins implicated in immune response and growth. Sci. Rep. 2017, 7, 5933. [CrossRef] [PubMed]

45. Zhang, Y.; Liu, Y.; Liu, H.; Tang, W.H. Exosomes: Biogenesis, biologic function and clinical potential. Cell Biosci. 2019, 9, 19. [CrossRef]

46. Bui, T.M.; Mascarenhas, L.A.; Sumagin, R. Extracellular vesicles regulate immune responses and cellular function in intestinal inflammation and repair. Tissue Barriers 2018, 6, e1431038. [CrossRef]

47. Chen, X.; Gao, C.; Li, H.; Huang, L.; Sun, Q.; Dong, Y.; Tian, C.; Gao, S.; Dong, H.; Guan, D.; et al. Identification and characterization of microRNAs in raw milk during different periods of lactation, commercial fluid, and powdered milk products. Cell Res. 2010, 20, 1128-1137. [CrossRef] [PubMed]

48. Zhang, H.; Wang, L.; Li, C.; Yu, Y.; Yi, Y.; Wang, J.; Chen, D. Exosome-Induced Regulation in Inflammatory Bowel Disease. Front. Immunol. 2019, 10, 1464. [CrossRef] [PubMed] 
49. Puppel, K.; Golebiewski, M.; Grodkowski, G.; Slosarz, J.; Kunowska-Slosarz, M.; Solarczyk, P.; Lukasiewicz, M.; Balcerak, M.; Przysucha, T. Composition and Factors Affecting Quality of Bovine Colostrum: A Review. Animals 2019, 9, 1070. [CrossRef] [PubMed]

50. Ulfman, L.H.; Leusen, J.H.W.; Savelkoul, H.F.J.; Warner, J.O.; van Neerven, R.J.J. Effects of Bovine Immunoglobulins on Immune Function, Allergy, and Infection. Front. Nutr. 2018, 5, 52. [CrossRef] 